UDK: 821.111(73).09-31 Морисон T.

\title{
- KRIZA IDENTITETA U ROMANU TONI MORISON KATRENO LUČE
}

\author{
BRANISLAVA LIČEN ${ }^{1}$, VESNA BOGDANOVIĆ 2 \\ Univerzitet u Novom Sadu, \\ Fakultet tehničkih nauka, Katedra za društvene nauke, \\ Novi Sad, Srbija
}

Roman Katreno luče Toni Morison, čiju narativnu osnovu predstavlja alegorijska priča o zecu koji uspeva da nadmudri belog lovca, ističe značenja pojmova crnog i katrana i pruža pogled na društveno raslojavanje afro-američke zajednice. Ovaj rad predstavlja identitete glavnih likova, Afro-Amerikanaca, prisutnih u romanu, njihove lične krize i (ne)mogućnosti pronalaženja sopstvenih identiteta u odnosu na društvo i na tradiciju. Ispituju se stereotipi prisutni u afro-američkoj zajednici, predstavljeni pre svega kroz društvenu hijerarhiju crnaca u romanu, kao i kroz identitet pojedinaca koji su zajednicu napustili. Kao i u većini drugih romana Morisonove, belci su prisutni marginalno, ali se u radu preispituju i njihovi identiteti. Iako su mnoga pitanja postavljena u ovom narativnom delu, završetak ne pruža odgovore vezane za rasne, klasne i kulturne konflikte, dok rad pruža pregled traganja za sopstvenom ulogom, postojanjem i korenima u okviru zajednice.

Ključne reči: afro-američki, kriza identiteta, kulturni identitet, ponos, katreno luče, rasni stereotipi.

\section{UVOD}

U romanu Katreno luče, Toni Morison koristi alegorijsku priču kao narativnu osnovu kako bi predstavila afro-američko društvo kao mikrostrukturu sveta. Klasna hijerarhija postavlja se između afro-američkih sluga više klase i onih koji se smatraju nižom klasom, kao i između ruralno i urbano odgojenih Afro-Amerikanaca. Klasna pripadnost Afro-Amerikanaca određuje se i na osnovu obrazovanja i poštovanja tradicije. Autorka predstavlja podeljenu afro-američku zajednicu iz perspektive

1 Kontakt podaci (Email): branalicen@gmail.com

2 Kontakt podaci (Email): vesna241@uns.ac.rs 
pojedinaca koji pokušavaju da u toj zajednici pronađu svoje mesto i svoj identitet. U radu će biti predstavljeno traganje glavnih junaka za sopstvenim identitetom u odnosu na zajednicu, tradiciju i obrazovanje. Biće prikazani ključni momenti koji su to traganje pokrenuli, kao i identiteti koje su likovi izgradili, odnosno identiteti kojima teže na kraju svog putovanja. Rad, kao ni sama autorka romana, ne nudi „autentičan“ afro-američki identitet, već samo predstavlja puteve kojima likovi idu i sukobe koji su ih nagnali na promenu putanje u ispitivanju sopstvenog bića.

\section{MOTIV AFRIČKOG FOLKLORA}

U roman je utkana narodna priča o „katrenom strašilu“, pojmu čije značenje u svojoj knjizi objašnjava Hortens Spilers (Spillers 1987: 32). Strašilo je beli farmer koristio kao zamku za zeca štetočinu, a ono nosi u sebi negativnu rasnu konotaciju jer se pojava može projektovati i na krajnje unižavajući način mučenja koji su beli robovlasnici sprovodili nad svojim robovima posipajući ih katranom i perjem radi ismevanja. Dodatno, katreno luče, odnosno tar baby na engleskom jeziku, jeste i način pogrdnog obraćanja belaca crnoj deci i ženama. Morisonova, međutim, u ovaj mit vešto uspeva da unese aspekat katrenog lučeta koji predstavlja pozitivnu karakteristiku afro-američkog identiteta. U afričkoj mitologiji se javlja žena od katrana, pa spisateljica boju, gustinu i kvalitet katrana izjednačava s iskonskim majčinskim, prirodnim i isceliteljskim kvalitetima crnkinja. Džejd, glavnoj junakinji romana, nedostaju ovi kvaliteti, ali se iskonska afrička snaga u svom najsirovijem obliku reflektuje u čoveku u koga se zaljubljuje. S druge strane, zec iz mita takođe navodi na ambivalentnost. U originalnoj priči, zec štetočina koji se hvata u zamku napravljenu od katrana, u simboličnom smislu u zamku "crnog", kako vreme protiče biva sve više i bolje zalepljen za katrenu lutku. Ipak, on svojom mudrošću na kraju uspeva da nadigra seljaka, koristeći svoje znanje o oholosti belaca kao svoj poslednji adut. Zec "moli farmera da radi s njim šta hoće, samo da ga ne baci u jamu, što će seljak i učiniti, nesmotreno puštajući time lukavog zeca na slobodu" (Kubitschek 1998: 108). Stoga, umesto negativne karakteristike štetočine koju mu pripisuje beli seljak, zec postaje oličenje afričke istrajnosti, mudrosti i borbe za nezavisnost.

Alegorijska osnova priče u narativnoj strukturi romana u prvi plan ističe analogiju između zeca i crnca. Crnac je ovde muškarac tamne boje kože koji potiče iz prirode i u prirodu se vraća. Ovaj muškarac, poput zeca, oslikava ruralni deo zajednice. Njega je moguće pripitomiti do određene mere (može da živi u Njujorku i da nađe posao, ali nije spreman da se usavršava i postane deo korporacijske Amerike), ali najbolje se oseća kada je pušten da bude jedno s prirodom (odnosno da prati fantomske jahače u divljem delu ostrva). Ovakvog muškarca, kao i zeca iz priče, moguće je uhvatiti u zamku od katrana, odnosno namamiti ga lepotom i prilepiti uz sebe. Međutim, kao deo ruralnog sveta, u srži njegovog postojanja nalazi se želja da ne bude sputan i vezan, da ne bude deo bračne zajednice ograničene društvenim i moralnim normama, te stoga beži iz sveta koji predstavlja zamku njegovom biću i vraća se u svet koji mu dozvoljava da ne menja sopstveni identitet.

Uzimajući afrički folklor za osnovu priče, Morisonova kroz intertekstualne asocijacije $\mathrm{i}$ alegoriju postiže kompleksnost $\mathrm{i}$ ambivalentnost što u velikoj meri 
otežava jednoznačno tumačenje romana. Koncept Katrenog lučeta na prvi pogled najviše podseća na ljubavnu priču u kojoj je crna žena katreno luče, ili zamka za crnog muškarca, zeca. Postavljeno je pitanje: šta jedna crnkinja koja je iskusila obrazovanje i prednosti zapadnog sveta može da ponudi muškarcu koji je istrčao iz „zečije jame"? Tokom svog rada na priči, spisateljica je imala u vidu sramotu i poniženje koji su implicirani u ovom izrazu, ali i mogućnost sagledavanja istog kroz prizmu nacionalnog ponosa. Razotkrivajući mit o katrenoj lutki kroz alegorijsku priču o zamkama koje stoje pred savremenim Afro-Amerikancima, u ovom ciljano uznemirujućem romanu Morisonova direktnim, često neprijatnim jezikom koji implicira poniženje i sramotu Afro-Amerikanaca obrađuje temu rasnog identiteta i klasne podeljenosti u crnoj zajednici, ali takođe romanu daje i univerzalnost teme.

\section{IDENTITETI GLAVNIH JUNAKA}

Glavna junakinja Džejd je crnkinja svetlije puti koju je u najbolje američke škole poslao Valerijan Strit, belac, naslednik fabrike šećera, poslodavac njenih tetke i teče, Ondine i Sidnija, sa kojima je odrasla. Ona je, s jedne strane, u romanu predstavljena kao zamka koju belci koji su je "stvorili” postavljaju za Sana, predstavnika crnaca niže klase i ruralnog porekla. Zatim, Džejd je žena kojoj nedostaju pozitivne osobine koje spisateljica pripisuje katranu: majčinske, hraniteljske osobine koje porodicu i članove zajednice drže na okupu. Takođe joj nedostaje i boja katrana, to jest intenzitet crnoće kože koji simboliše (ne)povezanost pojedinca s afričkim korenima. Pošto su na formiranje Džejdinog identiteta u velikoj meri uticali belci, San bi trebalo da joj ukaže na pravi put u potrazi za „autentičnim" crnim kulturnim identitetom. Sve pomenute okolnosti podstiču junakinju da se bori s krizom identita kroz ceo roman. Džejd povezuje crnoću, boju katrana, s ponosnom tamnoputom Afrikankom u žutoj haljini koja predstavlja moćni, svevremeni, gotovo mitski ženski lik koji sreće u samoposluzi i koji joj pljuje u lice. Njihov susret preokreće Džejdinu sanjalačku predstavu o crnkinji $\mathrm{u}$ žutom u bolno suočavanje $s$ rasnim i polnim aspektima svog identiteta s kojima se nije ranije uhvatila u koštac. Ona se oseća "usamljeno, neautentično" (Bouson 1999: 47-48). bel huks ističe da želja za znanjem može crnu ženu fizički udaljiti od njenih korena, porodice i tradicije, ali da su „crni ljudi ranjeni u našim srcima, razumu, telima i dušama" (hooks 1993: 11) i to je upravo osećanje koje preplavljuje Džejd. Nakon ovog događaja, junakinja preispituje svoj odnos sa Rikom, bogatim Evropljanom, koji je poznaje samo kao egzotičnu crnu lepoticu koja ispravlja svoju kovrdžavu kosu da bi se uklopila u zapadnjački ideal lepote, ali ne poznaje osobu koja je ispod te crne kože iz koje bi najrađe izašla kada bi mogla - da bi konačno bila samo ono što zapravo iznutra jeste, a ne definisana kao Amerikanka ili Afro-Amerikanka ili crnkinja ili bilo šta drugo. Autorka pokušava identitet svoje junakinje da poveže i sa zastrašujućim ženama koje vise s grana drveća, prebacuju joj i slute joj zlo nakon što se nađe zaglibljena u katrenom blatu. I dok one misle da je ona jedna od njih, odbegla da bi im se opet vratila, Džejd zapravo pokušava da se izvuče iz blata i pobegne od njih, čime postiže da one postaju „arogantne - svesne svojih vrednosti, svoje izuzetne ženstvenosti; znajući da je prvi svet svih svetova bio izgrađen na njihovim svetim osobenostima" (Bekerman 1978: 
59). Naglašavajući „svete osobine“ $i$ „,izuzetnu ženstvenost“ (Bekerman 1978: 60) žena iz močvare, Morisonova naglašava pozitivne osobine katrana, čime rasnu uniženost na koju katran isprva asocira preobražava u rasni ponos. Kasnije će Džejd u noćnim morama ponovo sresti te tradicionalne žene, a autorka koristi Džejdine strahove i more da verbalizuje duboku bojazan i anksioznost vezanu za "katrena" obeležja rasnog identiteta koji je, iz njene perspektive, večito prate, obeležavaju, guše i stigmatizuju.

Drugi ključni momenat koji u potpunosti menja Džejd i dovodi do želje za potpuno novim identitetom bližem afričkim korenima svakako je scena silovanja. Scena počinje njenim ponosnim prikazivanjem slika koje označavaju njenu karijeru, a završava se lažnim prikazom dešavanja koji je stvorila u svojoj glavi i s kojim ima nameru da se pojavi pred svetom. Maestralnom modernističkom tehnikom, Morisonova stavlja Sana pored Džejd u sceni u kojoj on nju fizički osvaja dok autorka bitne detalje ne izgovara, ne opisuje eksplicitno, već traži od čitaoca da zaključuje iz nagoveštenog. U sceni se isprepliću Sanova želja da se identifikuje sa svim drugim muškarcima koji su je imali (Morrison 1982: 103), njegova želja da njen identitet svede na identitet beznačajne kurvice („Silovanje? Zašto vi male belkinje uvek mislite da neko pokušava da vas siluje?" (Morrison 1982: 103)), njena potreba da sebe predstavi kao jaku i nezavisnu ženu ("0, dragi Bože, (...), čim me pustiš ubiću te." (Morrison 1982: 104)) i njeno ubeđenje da ljudi iz njenog okruženja mogu i hoće da joj pomognu („Valerijan će te ubiti, majmune, Sidni će te iseći na komade..." (Morrison 1982: 103)). Međutim, ostavši sama, Džejd sa užasom shvata da je privlači to divlje i primitivno ponašanje crnca kakvog davno nije videla, te nastavlja komunikaciju s njim kako bi iz sebe izvukla svoja prvobitna, primitivna osećanja.

Poistovećujući Sana s crnom ruralnom folklornom zajednicom, a Džejd s evroameričkom, urbanom, belom kulturom, Katreno luče suprotstavlja dve struje stalno prisutne na američkom tlu: suprotstavlja crno i belo, prirodu i civilizaciju, primitivno i kulturno, prljavo i čisto. Deo teksta posvećen je preokretanju belog hijerarhijskog sistema vrednostiveličanjem Sanovih afričkih (odnosno crnačkih, prirodnih, primitivnih) karakteristika. „Samo čovek koji je jeo čokoladu uveče i živeo poput životinje u potrazi za hranom i koji je bio tih poput zvezde mogao je to da uradi." (Morrison 1982: 89). Ipak, tekst oslikava Sanov lik s neospornom ambivalentnošću i zadrškom. On delimično u tekstu ostaje skriven, i u simboličnom smislu i bukvalno - u prvoj trećini romana - a kada se konačno pojavi, biva predstavljen čitaocu kao rasno Drugo, sramotni predmet prezira i mržnje, stereotipna iskrivljena slika Afro-Amerikanaca koji i sami tu sliku usvajaju i prihvataju je kao deo svog identiteta („,pocepan crnac koji se skrivao u ormanu njegove žene (sa silovanjem, krađom ili ubistvom na pameti)" (Morrison 1982: 78)). Kasnije u romanu, San je opisan kao osoba bliska prirodi i Africi, kao čovek kome se na licu i u očima mogu videti šume, prostranstva, planine i savane. Folklorne i herojske osobine koje mu se pripisuju prepliću se s osobinama "lošeg crnje", što je po afričkom narodnom predanju muškarac, snažan i borben, ali uvek oštro suprotstavljen kulturi i dominaciji belaca. Kroz dijalog između Sana i Džejd, dva suprotna pola na afro-američkoj lestvici obrazovanja i klase, čitalac saznaje za kulturološki jaz koji je duboko usađen u nasleđe viševekovne rasne uniženosti i klasnih raslojavanja. San i Džejd postaju ljubavnici, ali ne uspevaju da prevaziđu ove nepremostive razlike, između ostalog i zbog činjenice da ne mogu sa sigurnošću da odrede vlastite identitete pre nego što konstruišu 
zajednički identitet. Njihov zajednički identitet pokreće pitanje da li živeti u gradu, okružen zabavama, revijama, ali i stalnim i sigurnim zaposlenjem, ili živeti u ruralnom okruženju s prijateljima koje San poznaje od malena i koji insistiraju na patrijahalnom odnosu žene i muškarca. Iako prisutno samo marginalno, kroz Džejdine snove i žene koje joj se javljaju, jasno je da pitanje zajedničkog identiteta određuje i pitanje dece i porodice sa patrijarhalnim ulogama supružnika, od čega glavna junakinja beži veći deo svog života. Ova pitanja su uslovljena određenjem vlastitih identiteta glavnih junaka, koji oni u zajedničkom bivstvu ne mogu jasno da koncipiraju.

Sanov problem identiteta vuče korene od momenta kada je, nakon ubistva žene koju je zatekao s ljubavnikom, otišao od kuće. Bežeći od zakona, on je „[Z]a osam godina imao sedam dokumentovanih identiteta i pre toga nekoliko nedokumentovanih, pa se i sam jedva sećao svog pravog originalnog imena" (Morrison 1982: 119). Jedino blisko ime bilo mu je San, dok su „ostali ja bili poput reči koje je govorio - fabrikovani momenti, pogrešne informacije neophodne kako bi se San zaštitio od nedaća" (Morrison 1982: 119). Kriza identiteta ovog čoveka oslikava se u imenu koje je povezano s određenom ličnošću koju predstavlja drugim ljudima, ne sluteći da na taj način ističe svoju neprilagođenost pravilima savremenog društva od koga ima velika očekivanja. Ipak, iako „nije uvek znao ko je, (...) uvek je znao kakav je“ (Morrison 1982: 142), odnosno poznavao je srž svoga bivstva. Na njegovu nesreću, i to će se promeniti kada nakon poznanstva sa Džejd krene bez cilja da luta ostrvom Kavaljera.

Osim što suprotstavlja različite polaritete u okviru afro-američke zajednice, Katreno luče artikuliše i anti-kapitalističku i anti-imperijalističku poruku, opisujući kako su pojedinci poput Valerijana Strita, predstavnika belih evro-američkih osvajača Kariba, u svom pokušaju da pripitome i kontrolišu prirodu, istu zapravo uspeli da unište. Roman se suprotstavlja anglo-saksonskom normativu koji podrazumeva demonstraciju moći i vlasti belaca nad starosedeocima i ostvarenje njihovih ekonomskih interesa na Karibima. U binarnoj opoziciji dve rase, belci su prikazani marginalno, a njihov pad ih karakteriše kao ličnosti koje ne uspevaju da se uzdignu iznad problema. S druge strane, pripadnici afro-američke zajednice, iako razdvojeni klasnom hijerarhijom, obrazovanjem i tradicijom, uspevaju da na kraju romana ostanu da stoje uzdignute glave, sa planovima prilagođenim novonastaloj situaciji, te ih roman prikazuje kao jače, hrabrije, otpornije i sposobnije da prežive.

Autorka i samim okruženjem implicira krizu identiteta i ostrva i ostrvljana. Ostrvo je opisano kao rajska priroda gde se sa mora pruža pogled "tako milostiv da su se posetioci umarali gledajući sve to: tropske biljke, avokado, božićno drvo, limun, banana, kokosi poslednje šampionsko drveće prašume" (Morrison, 1982: 8). Istovremeno, ostrvu se pripisuje i određen broj mitskih elemenata - pojavljuje se drveće koje govori, starica čije su grudi uvek prepune mleka, fantomski ratnici, i slično. Kao što Patriša Kolins navodi, ubacujući ove elemente u roman, Toni Morison naglašava „značaj folklora i narodne tradicije na (ne)mogućnost određivanja identiteta i pripadnosti“" (Collins 2000: 123). Na taj način ostrvo i narodna tradicija postaju veoma važan element identiteta glavnih junaka, jer je u njihovim reakcijama i razmišljanjima jasno koliko pažnje posvećuju upravo tradiciji i prirodi i koliko ovi elementi određuju njihovo postojanje. A kontrast rajskoj prirodi ostrva nalazi se u ljudima koji su puni nemira i nedoumica, u negostoljubivosti močvare u koju upada Džejd, magli koja prati Sana na njegovom 
poslednjem putovanju, u stakleniku Valerijana Strita gde biljke ne uspevaju, kao i u samom vlasniku kuće Valerijanu koji po ceo dan sedi u stakleniku i ne pomera se zbog vrućine, mrava i misli koje ne uspeva da otera od sebe.

Belih likova u romanu ima svega nekoliko. Valerijan i njegova supruga žive u kući u kojoj se odvija veći deo romana, dok su ostali likovi prisutni jedino u pominjanjima da treba da dođu ili da se kod njih treba otići. Penzionisani bogataš, Valerijan Strit, provodi dane i godine na ostrvu boreći se sa vlastitim identitetima industrijalca, penzionera, poznavaoca Filadelfije koja više ne postoji, oca koji ne viđa svog sina i muža koji nema kontakta sa svojom ženom. Roman opisuje njegovu potrebu da kontroliše druge, uključujući i svoju suprugu, i prikazuje ga kao osobu koja očekuje da ljudi postupaju po njegovim naređenjima. Spisateljica karikira Valerijana dajući mu ime rimskog imperatora i nazivajući ga više puta u tekstu „kraljem slatkiša” (Morrison 1982: 65). A kada ga na kraju romana prikaže nemoćnog i utonulog u zaborav, Morisonova u potpunosti obrušava njegov identitet i život koji je gradio za sebe. Valerijanova žena, Margaret, veći deo godine provodi u Sjedinjenim Državama koje doživljava kao svoju domovinu. Njeni lični nemiri vezani su za poziciju gazdarice koja to ne zna da bude, majke koja nije dobro radila svoj posao i supruge koja ne razume svog supruga. Margaretin identitet gazdarice konstantno narušavaju Sidni i Ondin, koji vode domaćinstvo i obavljaju razne poslove na imanju Stritovih, ponašajući se kao gazde iako su samo sluge. A njen lični krah identiteta ostvaruje se kada Valerijan pozove stranca na večeru uprkos njenim molbama i psihičkom stanju. „Nije nikako spavala, i sada, iznurena od panike, lutajući između ljutnje i tuge, ležala je u krevetu. (...) Stranac koga su pronašli kako se krije u ormanu njegove žene, skitnica koju je čak i Sidni hteo da upuca, a on ga je pozvao da večera dok se ona tresla poput lista na vratima. U njenom ormanu." (Morrison 1982: 71).

Provokativnom i uznemirujućom analizom klasnih tenzija koje su u osnovi intra-rasnih i inter-kulturnih odnosa, Katreno luče govori i o začaranom krugu prezira koji određuje i obeležava odnos između crnog američkog para, Sidni i Ondin, i crnih ostrvljana Tereze i Gideona koji su zaduženi za obavljanje najtežih poslova na imanju. Uprkos njihovom niskom društvenom statusu, Sidni i Ondin su za stepenik više na klasnoj lestvici od ostrvskih crnaca. Kao idealni sluga, u prisustvu Stritovih, Sidni je spreman da postane nevidljiv: „Teško je bilo znati da li je napustio sobu ili je i dalje stajao u nekom njenom osenčenom uglu." (Morrison 1982: 62). Ali je on takođe i vredan čovek, , jedan od sposobnih filadelfijskih crnaca" (Morrison 1982: 140), najponosnijih ljudi crne rase. Ondin je, shodno tome, vredna i ponosna žena, koja je pre Sanovog dolaska u kuću potpuno zadovoljna svojim životom. Smatrala je da „živi u prelepom okruženju, uključujući i sopstvenu teritoriju gde je sama gospodarica" (Morrison 1982: 33). Džejd misli da je Ondin „umela da vlada iz sedećeg položaja” (Morrison 1982: 77), a Sidni takođe upoređuje Ondin s kraljicom: „njene teške, bele pletenice su joj stajale na glavi poput kraljevskih dijadema" (Morrison 1982: 83). Ovaj bračni par sebe vidi kao gospodare iz senke, kao osobe koje određuju životne navike belih gospodara i određuju poslove drugom, na lestvici nižem paru crnaca. Morisonova na mikroplanu odnosa ova dva para crnaca pokazuje kako moć, ma koliko mala, uzdiže ljude iznad onih koji nemaju pravo glasa i odluke, i kako takvi ljudi stvaraju svoj identitet u odnosu na njima podređene ljude, zanemarujući ostatak sveta. To je i razlog zašto Sidni i Ondin ni ne 
pokušavaju da doznaju imena Gideona i Tereze, već im dodeljuju imena koja sami lako upamte (baštovan i Meri).

Sidni i Ondin su zadovoljni identitetima koje su za sebe stvorili, shvativši tek nakon božićne večere da sve može da nestane ukoliko Valerijan tako odluči. Zadovoljni su i svojim afro-američkim srednjeklasnim statusom, naročito kada sebe vide superiornim u odnosu na crne ostrvljane prema kojima gaje dozu prezira. Tereza na prezir uzvraća prezirom, pa je Meri Helen Vašington opisuje kao ženu „kompleksne i strasne mržnje" (Washington 1989: 124), koja odbija da razgovara s crnim Amerikancima, a prisustvo belaca u svom okruženju potpuno ignoriše. Terezino ponašanje ima korene u tradiciji ostrva, u kojoj se veliča sve mitsko i crno a mrzi sve novo i nametnuto. Njeno ponašanje deluje kao mržnja prema svemu stranom sve dok autorka romana ne prikaže njenu ljubav prema Sanu kao osobi u kojoj vidi mitske i tradicionalne osobine i kojoj u svakom momentu želi da pomogne.

Ulaskom Sana u kuću na svetlo isplivavaju i rasne i klasne tenzije među samim Afro-Amerikancima. Zbog tih tenzija roman započinje epigrafom koji je citat iz poslanice Korinćanima: „Jer rekli su mi o vama, braćo moja, oni iz kuće Kloi, da među vama ima nesuglasica." (Morrison 1982: ii). Oni iz kuće Kloi bili bi svi oni koji su, kako stoji u posveti romana „sačuvali svoja istinska i iskonska obeležja“" (Morrison 1982: i)³. Iz navedenog se vidi da spisateljica koristi roman da protka i svoj osećaj pripadnosti i/ili izdvojenosti u okviru afro-američke zajednice, kao i pitanja vezana za vlastiti identitet žene, majke, spisateljice, Afro-Amerikanke.

\section{SUKOBI I KRIZE U ROMANU}

Sanov status stranca destabilizuje površnu harmoniju domaćinstva u koji ulazi da bi našao hranu, i ostaje, sakriven, jer ga neizmerno privlači Džejd. Kada Margaret naleti na stranca u svom ormanu, čitalac nazire veliku krizu. Pripiti Valerijan poziva Sana na večeru, ne uvažavajući protivljenje ukućana. Sanov kratak boravak u kući isprovociraće Margaretine rasističke komentare, prezir Sidnija i Ondin prema crncima niže klase, kao i Džejdina ambivalentna osećanja privlačnosti, odnosno odbojnosti prema njemu. Iako bez gotovo ikakvog zajedničkog iskustva, i sa vrlo malo zajedničkih vrednosti, San i Džejd ipak uspostavljaju duboku emocionalnu i seksualnu vezu. Započinju zajednički život, prvo u Njujorku gde se Džejd oseća prijatno, a zatim u mestu Eloi, na Floridi, gde je San odrastao. Tokom putovanja na površinu isplivava još jedna velika kriza u ovom romanu, jer se ni jedno od njih dvoje ne oseća prijatno u ambijentu koji je onom drugom dom. Džejd se u Eloiu u budnom stanju prikazuju duhovi tradicionalnih žena; ona odbacuje tradicionalne uloge personifikovane u njima, ali se pritom oseća neostvarenom, nepotpunom, neadekvatnom. Linden Pič ističe da je upravo „njihovo međusobno nerazumevanje u vezi sa različitim doživljajima afričke kulture i afričkih

3 Ovde se Morisonova poigrala igrom reči, jer je njeno pravo ime zapravo Chloe, ali ga je tokom studija promenila u Toni, jer su ga mnogi ljudi teško izgovarali. I upravo taj čin je, smatra Vilfred Semjuels, kasnije smatrala za „odvajanje od 'pravih vrednosti"' (Samuels/Weems 1991: 61), autentičnih afričkih obeležja, osećajući osudu svoje tradicionalne sredine. 
vrednosti uopšte" (Peach 1995: 73). Nakon neuspešne potrage za kompromisom, San i Džejd se rastaju.

Katrenoluče zatim prikazujeiposledice koje su proizašleiz nekoliko glavnih konflikata u romanu. Ondin smatra da Džejd ne razume obaveze i odgovornost deteta prema roditeljima, odnosno starateljima, čime se obrušava i deo njenog identiteta kao dobre kćeri. Nakon što njeni odnosi sa svim likovima u romanu postanu jalovi, Džejd odlučuje da jedino što sama može da učini da bi sebi pomogla jeste da se vrati u Evropu. U poslednjim scenama, Tereza čamcem prevozi Sana ka obali ostrva Kavaljera gde se on nada da će pronaći Džejd nakon što je shvatio da mu je potrebna. Doznavši da je već otišla, moraće da donese odluku da li želi da je prati ili da se pridruži fantomskim ratnicima s ostrva. Tereza podstiče Sana da napusti Džejd i pridruži se slepim jahačima. Činjenica da su jahači slepi, međutim, Madu Dubi vodi do zaključka da „prepuštanje tradiciji i korenima ne može Sana odvesti daleko, jer je na ostrvu jasno vidljiv napredak koji donosi imperijalizam i koji podrazumeva napuštanje tradicije" (Dubey 1994: 58). U završetku romana, koji je otvoren i krajnje ambivalentan, vidimo Sana kako poput zeca iz mita o katrenoj lutki, trči udaljavajući se od mesta na kome mu je postavljena zamka, pokušavajući da lukavo dostigne poreklo svojih korena i identiteta koji želi da mu pripadne.

\section{ZAKLJUČAK}

U romanu Katreno luče Toni Morison se bavi pitanjem potrage za identitetom u afro-američkoj zajednici i društvu kome pojedinac pripada. Katreno luče je veoma uznemirujuća priča koja otvoreno govori o rasnim stereotipima i predrasudama, koristeći jezik rasne netrpeljivosti, uvreda, prezira i mržnje koji je karakterističan za socijalnu, rasnu i klasnu podeljenost američkog društva. Nastavljajući svoj rad na prethodnim romanima, Morisonova u ovom romanu, kroz prizmu rasne i klasne, ali i polne podeljenosti, na izuzetno kompleksan način pristupa temi stvaranja autentičnog afro-američkog identiteta. Javno govoreći o klasnim tenzijama u okviru crne zajednice $s$ naglaskom na predrasude crne buržoazije prema Afro-Amerikancima niže klase, spisateljica ponovo ukazuje na štetan uticaj nasleđenih i usvojenih rasnih stereotipa i diskursa na afro-američki identitet $i$ kulturu.

Autorka romana ne teži da pruži jasne osobine onoga što bi trebalo da se predstavi kao „autentičan“ afro-američki identitet. Za Džejd, težnja za razrešavanjem konflikta identiteta je nešto što je istovremeno i privlači i porobljava, ono čime se ponosi, a što u njoj istovremeno izaziva stid i gađenje. Katreno luče, kroz odnos Sana i Džejd, suprotstavlja dva nepomirljiva identiteta: jedan koji je ona stekla pokušavajući da se asimiluje u evro-američkoj zajednici, i drugi, gotovo čisto rasni identitet, koji im je zajednički. Priča stoga ne daje odgovor na pitanje šta bi „autentičan“ identitet AfroAmerikanaca trebalo da bude, već ispituje različite vidove tog identiteta, koji u okvirima društva i zajednice u velikoj meri zavise od okolnosti.

Alegorijska struktura romana omogućila je autorki da rasno polarizovanu sredinu predstavi kao mikrostrukturu veće društvene zajednice. Svi junaci ispoljavaju rasne i klasne predrasude prema ljudima kojima su okruženi i svi imaju identitete kojima se predstavljaju, identitete koje su ostavili iza sebe, ali i identitete kojima teže. Bilo da se 
radi o slugama koji sebe vide kao domaćine, o ženi koja je uspešna po evro-američkim standardima ali nije ispunjena kao majka niti kao pripadnik svoje rase, o čoveku koji ne može svoje ruralno Ja da uklopi sa urbanim svetom, ili o čoveku koji urbani svet zamenjuje tišinom staklenika nadajući se da će sve pre toga jednostavno nestati, autorka koristi njihove unutrašnje nemire i nemogućnosti definisanja vlastitog Ja kako bi kroz prizmu više ličnih svetova prikazala mikrostrukturu klasno raslojenog društva i napisala roman koji svojom univerzalnošću podstiče čitaoca da preispita vlastite konflikte.

Morisonova poziva čitaoca da učestvuje u tekstu, da, po rečima Boni Anđelo, „sagleda i lice i naličje polnog, klasnog i kulturološkog konflikta" (Angelo 1989: 121) između Sana i Džejd, i da potencijalno dâ svoj sud i stavi se na stranu jednog od glavnih protagonista romana, što je i tipično za postmoderni roman. Ipak, roman umesto razrešenja, otvorenim završetkom otvara nove dileme. Džejd se vraća u Evropu, dok San ne uspeva da se otrgne od tradicije i korena i prilagodi se vremenu i svetu u kome živi. Ovaj muškarac, iako to pokušava, ne uspeva da odraste, te na kraju romana odlazi ka mitskom svetu afričkog folklora. Spisateljica u poslednjim pasusima opisuje Džejd kao snažnu i moćnu figuru, ali i kao ranjivu ženu kojoj neće biti lako da zaboravi ljubav $i$ strast koji su deo nje isto koliko su to i njene ambicije iželja za nezavisnošću. Umesto da razreši konflikt sa Džejd, spisateljica ostavlja Sana da se povuče iz društva prepuštajući se idealizovanom svetu afričkog mita, bez suočenja s problemima. Katreno luče ne razrešava konflikt između ljubavnika, niti unutrašnje konflikte likova u njihovom traganju za sopstvenim identitetom.

\section{LITERATURA}

Angelo, B. 1989. The Pain of Being Black: An Interview with Toni Morrison. Time, 22 May, $120-123$.

Bekerman, J. 1978. The Seams Can't Show: An Interview with Toni Morrison. Black American Literature Forum 2, 56-60.

Bouson, B. J. 1999. Quiet As It's Kept: Shame, Trauma, and Race in the Novels of Toni Morrison. Albany, New York: State University of New York Press.

Collins, P. H. 2000. Black Feminist Thought. New York: Routledge.

Dubey, M. 1994. Black Women Novelists and the Nationalist Aesthetic. Blooming and Indianapolis: Indiana University Press.

Hooks, Bell. 1993. Sisters of the Yam: Black Women and Self-Recovery. Cambridge, Massachusetts: South End Press.

Kubitschek, M. D. 1998. Toni Morrison: A Critical Companion. Westport, Connecticut: Greenwood Press.

Morrison, T. 1982. Tar Baby. New York: Plume.

Peach, L. 1995. Toni Morrison. New York: St. Martin's Press.

Samuels, W. and C. H. Weems. 1991. Toni Morrison. MELUS 17/4: 146-148.

Spillers, H. J. 1987. Mama's Baby, Papa's Maybe. Diacritics: A Review of Contemporary Criticism 17/2, 65-81.

Washington, M. H. 1989. Invented Lives: Narratives of Black Women 1860-1960. London: Virago Press. 


\section{SUMMARY}

\section{IDENTITY CRISIS IN TONI MORRISON'S TAR BABY}

Toni Morrison's novel Tar Baby, relating the tale of a rabbit outwitting the Caucasian hunter while interweaving all the meanings related to tar and black, provides an insight into social classes of African-American people on a Caribbean island. The main character Jade returns home from Europe only to find out that she does not belong there anymore. Falling in love with a mysterious stranger Sun, who represents all that she is not (native African, rural, traditional), intensifies her doubts in herself and her identity. Her personal crisis intermingles with Sun's, whose primitive being is challenged by Jade, disabling them to build an identity together. Morrison uses the novel to talk about stereotypes present in African-American community, to talk about hierarchical differences among those more or less black and more or less fortunate, and to question the identity of those who dare to be different and leave their community. As in most of her novels, white Americans with their personal crisis are marginalized in the novel. Although many questions are raised by black characters in this extraordinary piece of writing, the ending leaves the racial, class and cultural conflicts open.

KEYWORDS: African-American, identity crisis, cultural identity, national pride, tar baby, racial stereotypes.

(Originalan naučni rad primljen 08.04.2013; ispravljen 02.12.2013;

prihvaćen 20.12.2013) 